\title{
Application of Online Teaching Mode in Basic Programming Course
}

\author{
Weiwei Zhang \\ Beijing Wuzi University, Beijing 101149, China
}

ABSTRACT. The sudden new crown epidemic has caused a large number of online teaching methods to be used in teaching in colleges and universities, the basic programming course has some higher requirements for experimental conditions and interactions. This article analyzes the advantages and disadvantages of several teaching methods, and compares the advantages and disadvantages of the recorded course and live broadcasting mode in dealing with problems such as large differences in experimental conditions and interaction, put forward the idea of establishing a function-rich teaching platform for basic programming courses.

KEYWORDS: Online teaching, basic programming courses, teaching mode

\section{Introduction}

A sudden epidemic has caused many schools to implement online teaching. Many scholars have conducted research on the overall situation of online teaching. The basic programming course is for students who are learning programming for the first time. Students not only need to learn basic concepts and programming skills but also Basic ideas and algorithms, they also require a lot of practical operation and interaction. Which teaching modes are used in online teaching? The advantages and disadvantages of each mode? What are the problems? Is the teaching effective? Existing research has not been specifically analyzed, this article combines the actual teaching of the research.

\section{Types and tools of online teaching mode}

\section{Types of online teaching}

There are many types of online teaching, and many researchers have classified them according to their own standards (Bao W., 2020, Demuyakor, J., 2020, Chen, T. etc., 2020, Zhang, W., 2020), mainly including live broadcast, MOOC class, and synchronized classroom, On-demand, recorded, text and audio, software interaction, providing materials for self-study by students, TV classroom, etc. The basic programming courses adopted by the Beijing Wuzi University mainly include: (1)

Published by Francis Academic Press, UK 
Frontiers in Educational Research

ISSN 2522-6398 Vol. 3, Issue 10: 1-8, DOI: 10.25236/FER.2020.031001

MOOC, teachers upload learning materials (courseware, course videos with explanations, etc.) to the MOOC website in advance, and students learn by themselves, after uploading new materials such as teaching videos, Notify students through instant messaging software such as WeChat groups and QQ groups, students and teachers can also interact through the MOOC platform; (2) Recorded courses. Some teaching videos (such as the installation of programming software and solutions to various unsuccessful installations, etc.) are not included in the syllabus but are essential, and are not suitable to be added to the chapters of the MOOC platform .For related auxiliary videos, teachers use the recorded mode to record the video and send it to the WeChat group or designated network to guide students to complete; (3) Live broadcast, which is the most commonly used and the most direct mode to explain and interact with students; (4) Live broadcast, recorded broadcast, and MOOC are used together. Due to no prior preparation, some students did not bring their laptops with them during the winter vacation, and there may be no computers at home, or there are old computers, and they cannot directly install the current programming software. In order to deal with these situations, the channels that students can access are as far as possible to place teaching materials and videos.

\section{Use of online teaching tools and platforms}

Online teaching tools and platforms do not refer to tools and platforms dedicated to online teaching. In order to get better teaching effect in emergencies, teachers use almost all tools and platforms that may be used for online teaching. These are called "online teaching tools and platforms" here. Mainly include: (1) Course network management platform, which can generally upload, download file, send and receive homework, create certain teacher-student interaction activities, course data statistics, etc., such as MOOC platform, etc.; (2) File upload platform, perhaps you want to upload and download large-storage software, compilation environment, operating videos, etc., because some of the software required for programming is relatively large, it may take several hours to load using MOOC, or even unable to upload. At this time, Tencent corporate mailbox, Baidu SkyDrive etc. are often used; (3) Realtime audio and video tools, such as Tencent Conference, Tencent Classroom, DingTalk, Zoom, etc. Because colleges and universities did not postpone the start of school, online teaching was carried out directly at the beginning of the year. Teachers produced various online learning materials in a short time. Tencent conferences and Tencent classrooms have become widely used tools and platforms because they are free, easy to use, and effective during the epidemic; (4) instant messaging tools, such as WeChat and QQ.

Teachers almost have common characteristics in the use of online teaching tools and platforms: (1) All use instant messaging tools, such as WeChat and QQ. Since all teachers and students used WeChat and other instant messaging tools before the outbreak, there is no need to download and install it. It is very easy to add friends or establish WeChat groups among students, so it is easy for interactive Q\&A, course notifications, exchanges between students, and release of live links .The release of auxiliary files and videos can be carried out in a timely and convenient manner in the WeChat group. Because instant messaging tools have limitations on file size, sometimes teachers need to use a network disk, mailbox, etc., and sometimes a large 
Frontiers in Educational Research

ISSN 2522-6398 Vol. 3, Issue 10: 1-8, DOI: 10.25236/FER.2020.031001

file is packaged and divided into several small files before it can be sent to the WeChat group. (2) Almost all teachers use multiple tools and platforms. For example, in order to make beginner students have an intuitive perception, the software link of the compilation environment will be sent to the students. At this time, it can be published on the MOOC platform, and instant messaging tools. However, some students have difficulty downloading from the Internet. It can't be downloaded completely in one day, and there are many problems in the middle. Some students failed to install after downloading, some students' computer software conflicted with the newly downloaded software and could not be installed, and some other software could not be used after installation. Some students had different operating systems and the compilation environment did not have a corresponding version. At this time, they need help, guide students to install virtual machines, etc., but when beginner students see that a problem is solved and a new problem arises or can only run on the virtual machine, they are often afraid of difficulties. At this time, the teacher uses a variety of methods and tools, as long as it can help the beginner students to install successfully, whatever tools the students can use, the teacher will use the corresponding tools to give guidance. Of course, teachers need to install a variety of tools on their computers. When faced with problems encountered by different students, they often need to change to the programming environment of the student's computer and install software and record videos. Faced with more than 70 student computers of different ages, different models, and different operating systems, it may take a few days for this task to fully guide students to install them successfully. When teaching, live broadcast is the main method. Students can have interactive communication and have a sense of presence. The submission of homework generally requires students to use the MOOC platform and instant messaging tools. Students will inevitably have problems when doing programming exercises. The answering and answering interactions are generally through instant messaging tools, which can not only explain in text or audio, but also answer in pictures and videos. The recorded mode focuses on pre-preparation, concept explanation, example problem explanation, detailed operation process, debugging operation process and other things that take a lot of time. From the point of view of the teaching process, recorded courses, live broadcasting, MOOC, and instant messaging tools need to be properly used in order to smoothly solve various problems encountered in programming basic courses.

\section{Comparison of recorded course and live broadcasting mode}

Since programming basic courses require a combination of recorded and live broadcasting, this article analyzes these two modes.

\section{Resolution of different learning time}

The different study time here does not refer to the time difference. Some students have time difference. However, the survey found that the students in Xinjiang are two hours apart, that is, when the class is at $8 \mathrm{am}$, for Xinjiang students it is $6 \mathrm{am}$, but Xinjiang students can overcome the problems encountered, get up early every day to go to class. Some students are abroad, and they can all be solved. The 
Frontiers in Educational Research

ISSN 2522-6398 Vol. 3, Issue 10: 1-8, DOI: 10.25236/FER.2020.031001

different learning time mentioned here mainly refers to after the teaching has been carried out to a certain level. Some students did not bring the computer home during the winter vacation and did not have a computer at home. They could only use mobile phones to edit programs. Some students had computers at home. However, it is relatively old. It takes about tens of seconds to run an output statement. Some students did an accumulation operation of 100 times and it took more than 7 minutes. Some students can see the Program running result immediately. The difference in the experimental conditions of the students results in the asynchronous learning progress. The main method we adopt is to place recorded videos in the MOOC, live broadcast for explanations and demonstrations, and the writing process of longer and complex programs is also made into the form of recorded courses to facilitate students, they can watch without taking up class time. Live streaming tools like Tencent Classroom can record videos, and Tencent meetings require teachers or students to record the class. By the middle of the semester, the learning effect of unconditional practice programming can already be apparent.

\section{Network problem solving}

The network conditions are different in different areas where students live, and live teaching requires good network support from users. From the overall situation, students' mobile phone signals are relatively good. Although the live teaching videos are stuck, using the live recording function can allow students with network problems to watch later. When the network is congested, there will be delays in live streaming software such as Tencent Classroom,but generally within ten seconds, it is acceptable. The delay of the computer network has little effect on computers of different performance. Many qualified students use mobile phones and computers at the same time. They use mobile phones to attend classes and the computers to do experiment. Some students in the recorded courses choose to study when the network is unblocked, and their time is relatively free.

\section{Interactive implementation}

The interaction between teachers and students can give students a sense of presence, increase their interest in learning, and solve problems they encounter. Recorded courses can not only record course content, but also record related answers to a student's questions, including operation screen recording, resource explanation screen recording, etc., but there is a delay in time. In the live broadcast mode, interaction is easier to achieve. The interaction between students and teachers is slightly weak on the Tencent Classroom platform. Students can speak only after teachers allow students to speak. Students speak through words, and the tone is not easy to express. The input of long sentences also takes time. Tencent Meeting has obvious advantages in interaction. Because it is a meeting software, not only the meeting host (teacher) and students can speak in voice or text, but also can share the screen or open the camera, which provides convenience for interaction. The interaction between students is difficult to carry out in the recorded courses mode. In the live broadcasting mode, it can be carried out through the conference platform, instant messaging software, etc. The discussion and argument between the students 
Frontiers in Educational Research

ISSN 2522-6398 Vol. 3, Issue 10: 1-8, DOI: 10.25236/FER.2020.031001

makes the learning process more dynamic and is conducive to the depth of the learning.

\section{Sharing of high-quality teaching resources}

The recorded mode can be recorded repeatedly, which is more conducive to creating high-quality teaching videos. Teachers in the same course group can work together and share high-quality teaching resources. In the live broadcast mode, like offline teaching, different classes are taught by different teachers, and differences in teaching ability and level will inevitably cause differences in teaching effects.

5. Reliance on students' autonomous learning ability

In the recorded mode, the video is recorded in advance on the Internet, and students learn by themselves. Neither the teacher nor the system knows whether to watch it carefully or just let the system play. In order to understand the learning effects of students, teachers generally conduct tests through homework, experiments and tests. This form belongs to post-supervision, and students with weak independent learning ability often cannot achieve good learning results.

In live teaching, teachers and students can interact directly, and they can organize, guide and supervise almost like offline classrooms. When problems are found, they can be pointed out in time, and to a certain extent, students who are not capable of independent learning can be supervised. However, it takes a lot of time to debug and explain the program. The objective conditions of the students' computers cause certain progress differences. The online live broadcast process exposes some students' computer screens to everyone, and some students do not want to share their screens. The lectures, homework checks, and interactions in the live broadcast can urge students who are not strong in autonomous learning, but also need to pay attention to protecting the privacy of students.

\section{Summary}

Through the previous analysis, it can be seen that live broadcast and recorded courses have their own characteristics and advantages and disadvantages. The recorded courses mode has obvious advantages in solving the difference in learning time, network problems, and sharing high-quality teaching resources. In terms of the implementation of interaction and the dependence on students' self-learning ability, the live broadcast mode can stimulate students' interest and reduce the dependence on self-learning ability.

\section{Combined use of live broadcast and recorded courses}

Both live broadcast and recorded courses have their own advantages and disadvantages. In order to achieve better teaching effects, teachers generally use both live broadcast and recorded courses to use their respective advantages to avoid their respective disadvantages. In general, there are three ways:

1. Part of the teaching content is recorded courses, and part of the teaching content is live.

Published by Francis Academic Press, UK 
Frontiers in Educational Research

ISSN 2522-6398 Vol. 3, Issue 10: 1-8, DOI: 10.25236/FER.2020.031001

For example, the installation and debugging of the compilation experiment environment, the installation of the virtual machine, the writing and debugging process of the case program code, the extended explanation of the basic concepts, etc., the teacher team records the video in advance, so that the students can watch the control multiple times during the experiment, and It can help students who experimented unconditionally at that time to refer to it when they have conditions afterwards. The basic programming class has only 32 hours. The live teaching makes full use of these hours. It not only explains concepts, rules, and algorithms, but also needs to communicate with students and answer common questions raised by students.

2. Recorded courses, live broadcast and flipped classroom mode. During the period of the epidemic, students were not in school. The flipped classroom mode of recorded courses and live broadcasting converts the instructional homework or experiment in the classroom into an interactive process of online live broadcast. The autonomous learning before class is still the teaching video recorded in advance. However, in the scene of online teaching in schools, this method will have some drawbacks. Because there are dozens of students in the class, the teacher cannot observe the screens shared by dozens of students at the same time and give guide. The switching of different screens, different students' Switching and switching between different software takes time and is not efficient. Discussions between students are also difficult to proceed smoothly, because it is hard to hear clearly when they speak at the same time, and the exchange of speeches one by one will also take up a lot of time, making the course progress slow.

3. Recorded courses and live broadcasting integration mode. This method may be more suitable for class teaching, and has been used more in practice. Before class, students watch the related videos recorded by the teacher. In the class, some key content teachers still play the recorded content again or conduct live explanations again, and conduct activities such as interaction, so as to understand the student's mastery level based on student feedback. The learning effect of the preclass video depends on the students' independent learning ability and experimental conditions. The learning effect may vary greatly. After discovering it in the online live broadcast, you can answer, supervise, and adjust the rhythm and content of the live teaching in time. After the live class, the submission of homework and experiments is done by the students themselves, but if the comments and guidance on homework and experiments are conducted through the recorded class, it is difficult to give feedback in time, and the live class will take up a lot of time. Generally, the teaching platform or instant messenger are used simultaneously.

\section{Thinking on the future development of online teaching of programming basic courses}

Teaching during the epidemic has caused many scholars to think about future development and put forward many suggestions, such as improving network conditions, improving the training of teachers and students in using online teaching equipment, and focusing on high-quality teachers to record and broadcast videos. 
Frontiers in Educational Research

ISSN 2522-6398 Vol. 3, Issue 10: 1-8, DOI: 10.25236/FER.2020.031001

These are also included in basic programming courses. The characteristics of the basic programming course make this course have its own needs, and we think it can be improved in the following areas:

1. Improve teaching tools and platforms. In response to the outbreak of the epidemic, teachers generally use a variety of methods to achieve better learning results. The platforms used by different teachers also vary from person to person. Switching between different platforms reduces efficiency. There are some related courses on the MOOC platform, but the progress, textbooks, difficulty, etc. may not be suitable for the students of this school. Some courses or some knowledge points of the courses are used as supplementary materials for students to watch. Teachers need to browse in advance to find out that they are close to their students' needs. For the various problems encountered in the experiment, very few are involved in the MOOC, but there will be a small amount of resources on video websites, and teachers can also push links to students in need after selection. Because students conduct programming experiments at home, the difference in experimental conditions makes many different problems, the teacher can record videos, but a video may only be for one or several students in the class, and the number is large. Multiple materials need to be placed in the network. The platform will take up a lot of storage space and network resources. Therefore, if teaching tools and platforms can not only perform recorded courses, live broadcasting, course management, homework submission, instant interaction, data analysis, etc., but also provide storage of infrequent resources, and students can retrieve them on demand, which can reduce some duplication of work in the future.

2. Strengthen the construction of basic programming curriculum resources. The differences in programming languages, teaching content, students' learning ability and self-discipline make it necessary for teachers to record suitable teaching videos in time. MOOC resources often attach importance to the system and completeness of the courses. Many MOOCs are also organized according to knowledge points. However, teachers' understanding of teaching content is different; teachers should also consider whether the content is suitable for the level of students in the class, and the difference in course content and progress. Many teachers have difficulty making full use of open MOOC resources. Teachers continue to accumulate resources for the actual teaching needs of their students in their class. For example, the explanation of a certain knowledge point can be carried out according to the level of the students in the class, and the writing of a case can be recorded according to the feedback of the students in the class, and a large number of designs can be designed Targeted as a resource library. A large number of well-made auxiliary videos will help improve the quality and efficiency of online teaching.

\section{References}

[1] Bao W. COVID-19 and online teaching in higher education: A case study of Peking University. Hum Behav \& Emerg Tech. 2020; 2: 113-115.

[2] Demuyakor, J. (2020). Coronavirus (COVID-19) and Online Learning in Higher Institutions of Education: A Survey of the Perceptions of Ghanaian International 
Frontiers in Educational Research

ISSN 2522-6398 Vol. 3, Issue 10: 1-8, DOI: 10.25236/FER.2020.031001

Students in China. Online Journal of Communication and Media Technologies, 10 (3), e202018.

[3] Chen, T.; Peng, L.; Yin, X.; Rong, J.; Yang, J.; Cong, G. Analysis of User Satisfaction with Online Education Platforms in China during the COVID-19 Pandemic. Healthcare 2020, 8, 200.

[4] Zhang, W.; Wang, Y.; Yang, L.; Wang, C. Suspending Classes without Stopping Learning: China's Education Emergency Management Policy in the COVID-19 Outbreak. J. Risk Financial Manag. 2020, 13, 55 